\title{
Amygdala Is Critical for Stress-Induced Modulation of Hippocampal Long-Term Potentiation and Learning
}

\author{
Jeansok J. Kim, ${ }^{1}$ Hongjoo J. Lee, ${ }^{1}$ Jung-Soo Han, ${ }^{2}$ and Mark G. Packard ${ }^{1}$ \\ ${ }^{1}$ Department of Psychology, Yale University, New Haven, Connecticut 06520-8205, and 2Department of Psychology, \\ Johns Hopkins University, Baltimore, Maryland 21218
}

\begin{abstract}
Stress is a biologically significant factor shown to influence synaptic plasticity and memory functioning in the hippocampus. This study examined the role of the amygdala, a brain structure implicated in coordinating stress behaviors and modulating memory consolidation, in mediating stress effects on hippocampal longterm potentiation (LTP) and memory in rats. Electrolytic lesions of the amygdala effectively blocked the adverse physiological and behavioral effects of restraint and tailshock stress, without impeding the increase in corticosterone secretion to stress. Physiologically, hippocampal slices from stressed animals exhibited impaired LTP relative to slices from unstressed control animals, whereas hippocampal slices from stressed animals
\end{abstract}

It is well documented that adverse effects on cognitive functioning generally accompany stress (Maier and Seligman, 1976). Although the acute response to stress (e.g., heightened cognition) is an adaptive mechanism, excessive stress, in particular uncontrollable stress, can have severe repercussions ranging from impairments in learning and memory to enhanced susceptibility to neuronal cell death (for review, see McEwen and Sapolsky, 1995; Kim and Yoon, 1998).

The hippocampus, as part of a system necessary for the formation of stable memory (Scoville and Milner, 1957; Eichenbaum et al., 1992; Squire and Zola, 1996), is enriched with receptors for corticosteroids (the principal glucocorticoid secreted by the adrenal cortex in response to stress; cortisol in humans, corticosterone in rats) and participates in terminating the stress response via the glucocorticoid-mediated negative feedback of the hypothalamuspituitary-adrenal axis (McEwen and Sapolsky, 1995). In the rat hippocampus, corticosterone has been shown to regulate metabolic, physiologic, and genomic functions of neurons (Sapolsky, 1992). As a result, certain hippocampal functions appear to be susceptible to stress, possibly linking the effects of glucocorticoids to cognitive functions such as learning and memory. For example, stress and corticosterone have been shown to impair hippocampal-dependent forms of verbal memory in humans (Bremner et al., 1993; Newcomer et al., 1999) and spatial memory in rats (Diamond et al., 1992; Luine et al., 1994; Bodnoff et al.,

\footnotetext{
Received Sept. 18, 2000; revised Feb. 16, 2001; accepted April 19, 2001.

This work was supported by a grant from the Whitehall Foundation, a Yale Pepper Pilot grant, and a Yale Junior Faculty Fellowship to J.J.K., National Institutes of Health Grant R29MH56973 to M.G.P., and National Institute of Mental Health Grant P4000 D51-2055 to Michela Gallagher. We thank Michela Gallagher for invaluable comments on this manuscript.

Correspondence should be addressed to Jeansok Kim, Department of Psychology, 2 Hillhouse Avenue, Yale University, New Haven, CT 06520-8205. E-mail: jeansok.kim@yale.edu.

Copyright (c) 2001 Society for Neuroscience $0270-6474 / 01 / 215222-07 \$ 15.00 / 0$
}

with amygdalar lesions exhibited normal LTP. Behaviorally, stressed animals were impaired in retention of a hippocampaldependent hidden platform version of the Morris water maze task, and this impairment was blocked by amygdalar lesions. In a fixed location-visible platform water maze task that can be acquired by independent hippocampal and nonhippocampal memory systems, stress enhanced the use of nonhippocampal-based memory to acquire the task. These results indicate that an intact amygdala is necessary for the expression of the modulatory effects of stress on hippocampal LTP and memory.

Key words: hippocampus; learning; fear; emotion; glucocorticoids; corticosterone; synaptic plasticity
1995; de Quervain et al., 1998). Consistent with these behavioral data, both in vitro and in vivo electrophysiological studies indicate that stress impairs hippocampal LTP (Foy et al., 1987; Shors et al., 1989; Diamond et al., 1992; Shors and Dryver, 1994; Kim et al., 1996; Xu et al., 1997), a putative cellular mnemonic mechanism (Morris et al., 1990; Bliss and Collingridge, 1993) (but see Shors and Matzel, 1997). If the notion that changes in synaptic efficacy are essential for learning and memory [e.g., Hebb's postulate; Hebb (1949)] is correct, then it is possible that the LTP impairment associated with stress might be one neural basis for stress-induced alterations in learning.

Considerable evidence indicates that the amygdala is critically involved in mediating stress-related effects on behavior and modulating hippocampal function. For example, amygdalar lesions and/or pharmacological manipulations have been shown to (1) prevent stress-induced gastric erosion (Henke, 1981, 1990) and analgesia (Helmstetter, 1992), (2) block memory modulatory effects of intrahippocampally administered drugs (Roozendaal et al., 1996, 1998; Packard and Chen, 1999), and (3) impair in vivo dentate gyrus LTP in the hippocampus (Ikegaya et al., 1994, 1995, 1996). In addition, the amygdala has been implicated in emotional learning (Kim et al., 1993; LeDoux, 1994; Maren and Fanselow, 1996) and attention (Gallagher and Schoenbaum, 1999; Holland et al., 2000). Anatomically, the amygdala projects to several hippocampal regions (including the CA1 area) (Krettek and Price, 1977; Aggleton, 1986), providing various routes by which it may potentially influence hippocampal function. Therefore, the present series of experiments examined the possibility that the amygdala is involved in mediating stress effects on hippocampal LTP and hippocampal-dependent learning, using a hidden platform version of the Morris water maze task. In view of evidence that memory is organized in multiple brain systems (Packard et al., 1989; Squire and Zola, 1996; Thompson and Kim, 1996), we also examined whether stress might influence learning in a 
task in which both hippocampal-dependent and hippocampalindependent memory systems appear to be engaged (McDonald and White, 1994). Specifically, we hypothesized that a selective impairing effect of stress on hippocampal memory processes would enhance the use of hippocampal-independent memory in acquiring this task.

\section{MATERIALS AND METHODS}

Subjects. Experimentally naïve male Charles River Long-Evans rats (270-300 gm) were individually housed in a climate-controlled vivarium on a $12 \mathrm{hr}$ light/dark cycle (lights on at 7:00 A.M.) with ad libitum access to food and water. The animals were handled daily for $7 \mathrm{~d}$ before surgery. All experiments were conducted during the light phase of the cycle.

Surgery. Under ketamine $\mathrm{HCl}(30 \mathrm{mg} / \mathrm{kg})$ and xylazine $(2.5 \mathrm{mg} / \mathrm{kg})$ anesthesia, subjects were mounted in a stereotaxic instrument (Stoelting, Wood Dale, IL), and bilateral amygdalar lesions were made by passing constant current $(1.5 \mathrm{~mA}, 15 \mathrm{sec}$; Ugo Basile, Comerio, Italy) through a stainless steel insect pin (\#00) that was insulated with epoxy, except for $\sim 0.5 \mathrm{~mm}$ at the tip (coordinates: from bregma, $-2.3 \mathrm{~mm}$ posterior, \pm 4 and $\pm 5 \mathrm{~mm}$ lateral, and -8.4 and $-8.8 \mathrm{~mm}$ ventral from the skull) (cf. Kim et al., 1993). For operated sham controls, the electrode was lowered to the amygdala without passing current. After surgery, all animals were given between 2 and 5 weeks to recover and acclimate to daily handling.

Stress paradigm. Half of the animals from sham and lesion groups were restrained in a Plexiglas tube and exposed to 60 tailshocks $(1 \mathrm{~mA}$ intensity, $1 \mathrm{sec}$ duration, 30-90 sec variable intershock interval), whereas the remaining animals were left undisturbed (four groups: sham-control, sham-stress, lesion-control, lesion-stress). This stress procedure, adapted from the "learned helplessness" paradigm (in which animals undergo an aversive experience under conditions in which they cannot perform any adaptive response) (Seligman and Maier, 1967; Maier and Seligman, 1976), has been demonstrated to be effective in altering subsequent synaptic plasticity in the hippocampus (Foy et al., 1987; Shors et al., 1989; Kim et al., 1996).

In vitro electrophysiology procedure. Promptly after stress, animals were decapitated under halothane anesthesia, and hippocampal slices were prepared in a standard manner (cf. Teyler, 1980). In brief, transverse hippocampal slices $(400 \mu \mathrm{m})$ were maintained in an interface recording chamber (Fine Science Tools, Foster City, CA) and continuously perfused $(\sim 2 \mathrm{ml} / \mathrm{min})$ with $95 \% \mathrm{O}_{2}$ and $5 \% \mathrm{CO}_{2}$ saturated artificial CSF [(in mM) $124 \mathrm{NaCl}, 3 \mathrm{KCl}, 1.25 \mathrm{NaH}_{2} \mathrm{PO}_{4}, 1 \mathrm{MgSO}_{2}, 26 \mathrm{NaHCO}_{3}, 3$ $\mathrm{CaCl}_{2}$, and 10 glucose] at $32^{\circ} \mathrm{C}$. After at least $1 \mathrm{hr}$ of incubation, a concentric bipolar electrode (inner contact diameter, $25 \mu \mathrm{m}$ ) delivering $100 \mu \mathrm{sec}$ pulses stimulated the Schaffer collateral-commissural fibers. A glass electrode filled with $2 \mathrm{M} \mathrm{NaCl}(1.5-2.5 \mathrm{M} \Omega)$ was placed in the stratum radiatum in CA1 under a microscope to record field EPSPs (f-EPSPs). The test stimulus intensity was adjusted to produce a response that was $50 \%$ of the maximum evoked responses. Baseline synaptic transmission was monitored for $20 \mathrm{~min}$ (every $20 \mathrm{sec}$ ) before delivering a tetanus [five trains of $100 \mathrm{~Hz}$, each lasting $200 \mathrm{msec}$ at an intertrain interval (ITI) of $10 \mathrm{sec}$. The f-EPSPs (amplified in the band of 0.1-5000 $\mathrm{Hz}$ ) were monitored up to $1 \mathrm{hr}$ after the tetanus. During the tetanus, f-EPSPs that were evoked by the first pulse in each of the five trains were recorded to assess the development of potentiation. Data were collected and analyzed on-line using a computer program written in AxoBasic/ QuickBasic (Axon Instruments, Foster City, CA). The initial (negative) slope of f-EPSPs was used in statistical analyses (cf. Kim et al., 1996). Only those slices that exhibited a stable baseline for $20 \mathrm{~min}$ were included in the analysis. The change in f-EPSPs after tetanus was averaged across slices for each rat (usually two hippocampal slices per rat). The magnitude of LTP was measured between 40 and $60 \mathrm{~min}$ after the tetanus, and statistical comparisons were made to the 20 min baseline measure.

Corticosterone radioimmunoassay. During the hippocampal slice preparation, trunk blood was collected for corticosterone radioimmunoassay. Blood serum was separated by centrifugation (5000 rpm, $20 \mathrm{~min}$ ) and stored at $-80^{\circ} \mathrm{C}$ until the time of assay. Serum corticosterone was measured using the radioimmunoassay kit of ICN Biomedicals (Carson, CA) with ${ }^{125}$ I-corticosterone as a tracer.

Hidden platform water maze task. The training and testing procedures were adapted from those previously described and have been shown to be hippocampal-based (Packard and McGaugh, 1994; Packard and Teather, 1998). After stress or not (in the manner described above), experimentally naïve amygdalar lesion and sham animals were placed back in their home cages for 30-60 min before undergoing eight massed training trials
(1 min ITI) to find a fixed submerged platform and escape from a circular water maze (diameter, $2.0 \mathrm{~m}$; height, $0.7 \mathrm{~m}$; water temperature, $23^{\circ} \mathrm{C}$ ). The starting point was randomly distributed across the four quadrants (two starting points per quadrant; the animal always faced the wall when placed in the water). If escape did not occur within $60 \mathrm{sec}$, the animal was manually guided to the platform. On finding the platform, the animal remained on the platform for $30 \mathrm{sec}$ and then was placed in a holding cage for another $30 \mathrm{sec}$ before the next trial. After the last trial, the animals were returned to their home cages. The next day, a retention test (a $60 \mathrm{sec}$ probe trial) was given in which the platform was removed from the pool. Animals' movements and the time taken to reach the position at which the platform had been located in training were monitored automatically using a computerized Poly-Track Video Tracking System (San Diego Instruments, San Diego, CA).

Two days after the spatial memory test, all animals were tested for fear conditioning to validate the functional effectiveness of the amygdalar lesions. After $3 \mathrm{~min}$ of baseline in a modular operant test cage (Coulbourn Instruments, Allentown, PA), animals were presented with three unsignaled footshocks ( $1 \mathrm{~mA}, 1 \mathrm{sec}, 1 \mathrm{~min}$ intershock interval) through the floor grid, which was wired to a Coulbourn precision-regulated animal shocker. Fear conditioning was monitored during the three $1 \mathrm{~min}$ intershock intervals by measuring freezing behavior using a 24-cell infrared activity monitor that detects movement of an emitted infrared $(1300 \mathrm{~nm})$ body heat image from the animal in the horizontal and vertical planes (cf. Lee and Kim, 1998). Immediate postshock freezing has been shown to accurately assay fear conditioning (Kim et al., 1992, 1993).

At the completion of behavioral testing, the subjects were overdosed with ketamine $\mathrm{HCl}$ and xylazine and perfused intracardially with $0.9 \%$ saline, followed by $10 \%$ buffered formalin. The brains were removed and stored in $10 \%$ formalin for at least 2 weeks before slicing. Transverse sections $(60 \mu \mathrm{m})$ were taken through the extent of the lesion, mounted on gelatinized slides, and stained with cresyl violet and Prussian blue dyes.

Fixed location-visible platform water maze task. The training and testing procedures were adapted from McDonald and White (1994), who demonstrated that this task is acquired by independent hippocampal-based and dorsal striatal-based memory systems. Naïve animals (no surgery) were exposed to stress or not and then placed back in their home cages for 30-60 min before undergoing eight massed trials (1 min ITI) to find a fixed submerged platform coupled with a visually salient pole (a black and white striped plastic strip; $15.2 \times 1.2 \mathrm{~cm}$ ). As with the hidden platform task, the starting point was randomly distributed across the four quadrants. On finding the platform, the animal remained on the platform for $30 \mathrm{sec}$ to explore its surroundings and then was placed in a holding cage for another $30 \mathrm{sec}$ before the next trial. After the last trial, animals were placed back in their home cages. The next day, a retention test was given in which the platform (coupled with the pole) was moved to a novel location. Animals were placed into the pool facing the wall equidistant from the previous and new platform locations, and their movements were tracked.

\section{RESULTS}

Figure 1 shows a photomicrograph of a transverse brain section stained with cresyl violet and Prussian blue from a typical rat with bilateral electrolytic lesions in the amygdala. Amygdaloid damage typically involved the majority of central and basolateral-lateral nuclei and small portions of the amygdala-striatal transition area.

As shown in Figure $2 A$, hippocampal slices from sham-stress animals exhibited impaired LTP (normalized f-EPSP slopes measured 40-60 min after the tetanus: $107.2 \pm 6.3 \%$ ), whereas LTP was robust in slices from sham-control (149.2 $\pm 3.0 \%)$, lesioncontrol $(140.9 \pm 4.7 \%)$, and lesion-stress $(139.4 \pm 6.5 \%)$ animals (two-way ANOVA; lesion $\times$ stress interaction: $F_{(1,27)}=11.5, p<$ 0.01 ; planned comparisons: $F_{(3,27)}=8.5$, all $p$ values $<0.01$ Newman-Keuls). There was a significant main effect of stress on $\operatorname{LTP}\left(F_{(1,27)}=10.4, p<0.01\right)$, but no reliable main effect of lesion on $\operatorname{LTP}\left(F_{(1,27)}=3.6, p>0.05\right)$, indicating that the amygdalar lesions did not reduce the magnitude of LTP per se but did effectively block stress-induced impairments in LTP.

Examination of blood corticosterone levels (Fig. 2B) revealed significantly higher levels in animals exposed to stress than in those not exposed to stress, irrespective of the lesion, (two-way 


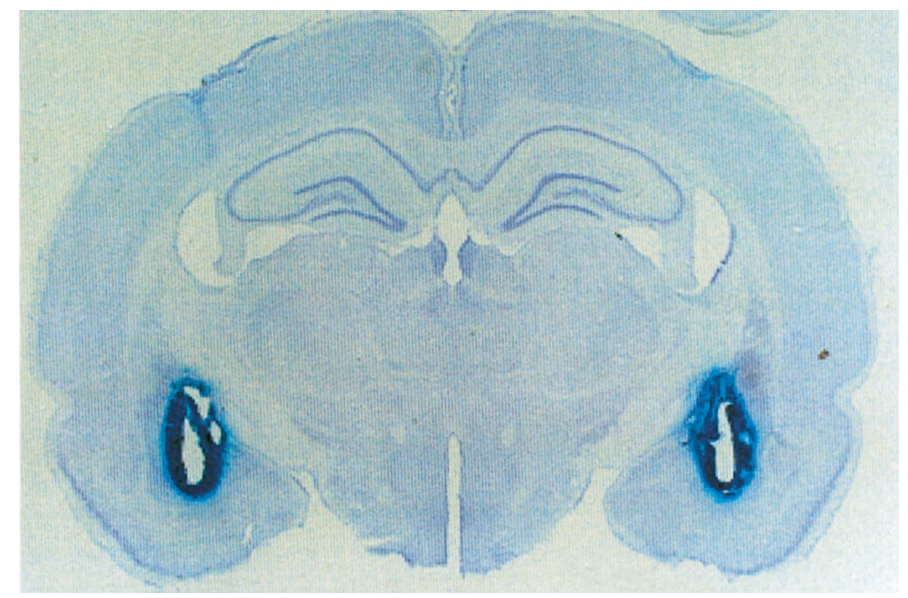

Figure 1. Photomicrograph showing a transverse brain section stained with cresyl violet and Prussian blue from a rat with amygdalar lesions.

ANOVA; main effect of stress: $F_{(1,27)}=78.9, p<0.01$; main effect of lesion: $F_{(1,27)}=2.3, p>0.05$; lesion $\times$ stress interaction: $\left.F_{(1,27)}=1.3, p>0.05\right)$. Although there appears to be a trend of lesion-stress animals $(49.7 \pm 7.8 \mu \mathrm{g} / \mathrm{dl})$ showing a lesser amount of stress-induced corticosterone elevation than sham-stress animals $(65.0 \pm 7.6 \mu \mathrm{g} / \mathrm{dl})$, this difference was not statistically reliable, $(p>0.05$, Newman-Keuls). This indicates that amygdalar lesions do not affect stress-induced elevations in corticosterone levels.

In a hippocampal-dependent hidden platform version of the water maze task, all groups significantly decreased their latencies to find the hidden platform during the eight training trials (Fig. $3 A$ ). The rate of acquisition was comparable among the four groups (two-way ANOVA with trials as a repeated measure; main effect of lesion: $F_{(1,31)}<1.0, p>0.05$; main effect of surgery: $F_{(1,31)}=2.7, p>0.05$; lesion $\times$ stress $\times$ trials interaction: $F_{(7,245)}$ $<1.0, p>0.05$ ). On the retention (probe) test a day later, however, the lesion animals required significantly shorter latencies to swim to the original location of the platform than the sham animals, irrespective of stress (two-way ANOVA; $F_{(1,34)}=13.5$, $p<0.01)$. Although neither the main effect of stress nor lesion $\times$ stress interaction was significant (two-way ANOVA; $F_{(1,34)}=3.0$, $p>0.05$, and $F_{(1,34)}=1.4, p>0.05$, respectively), a simple planned comparison analysis indicated that the sham-stress animals $(39.1 \pm 8.4 \mathrm{sec})$ exhibited significantly longer latencies to swim to the original location of the platform, in comparison to the sham-control $(22.7 \pm 3.9 \mathrm{sec})$, the lesion-control $(9.8 \pm 2.5 \mathrm{sec})$, and the lesion-stress $(12.9 \pm 4.7 \mathrm{sec})$ animals (one-way ANOVA; $F_{(3,34)}=6.1$, all $p$ values $<0.05$ Newman-Keuls). The latency differences cannot be attributed to possible motoric effects because there were no reliable group differences in swim speed $(p>0.05)$ (Fig. 3B). Also, the swim distance-dependent measure provided the same results as the latency-dependent measure (data not shown). Thus, these results suggest that amygdalar lesions may enhance retention of the hidden platform task and also effectively block the impairing effects of stress on this task.

Using the present training parameters in which rats are trained in a single rapid session (eight trials per $60 \mathrm{sec} \mathrm{ITI),} \mathrm{none} \mathrm{of} \mathrm{the}$ groups subsequently demonstrated a reliable quadrant bias or difference in number of quadrant entries per annulus crossing on the probe trial given $24 \mathrm{hr}$ later (data not shown). However, on the probe trial, the sham-stress animals had significantly longer latencies to reach the location of the platform and swam significantly longer distances to reach this location, compared with shamcontrol, lesion-control, and lesion-stress animals. Importantly, the significance in the latency measure was not attributable to a difference in swim speed between the four groups of animals. Although a reliable spatial bias was not observed in unstressed animals during the probe trial, it should be noted that previous drug infusion studies (Packard et al., 1994; Packard and Teather, 1998) have shown the current training and testing procedures (using the latency and distance measures) to be hippocampal-based.

In addition to histological verification (Fig. 1), the effectiveness of the lesions was confirmed by observations that animals with amygdalar lesions exhibited virtually no freezing after footshocks (main effect of lesion: $F_{(1,34)}=171.8, p<0.01$ ) (Fig. $3 B$ ). Previous experience with stress ( $3 \mathrm{~d}$ before fear conditioning) did not reliably affect fear conditioning in either lesion or sham groups (no lesion $\times$ stress interaction: $F_{(1,34)}=0.02, p>0.05$ ).

In the fixed location-visible platform water maze task, an ANOVA with group as a between-subject factor and trials as a repeated measure revealed that there was no reliable difference between stress and control animals during the eight acquisition trials $\left(F_{(7,140)}=1.5, p>0.05\right)$ (Fig. $\left.4 A\right)$. On the retention test $(24$ hr later), with the platform (marked with the same salient pole) moved to a new location, animals stressed before training exhibited a significantly shorter latency to swim to the platform than unstressed control animals $\left(F_{(1,19)}=4.7, p<0.05\right)($ Fig. $4 A)$. The control animals exhibited longer latencies to escape because they
Figure 2. Effects of amygdalar lesions and stress on Schaffer collateral-commissuralCA1 LTP and corticosterone secretion. $A$, Synaptic strength in the CA1 area of the hippocampus from sham-control (open circles, $n=6$ ), sham-stress (filled circles, $n=6$ ), lesion-control (open triangles, $n=8$ ), and lesion-stress ( filled triangles, $n=8$ ) animals is expressed as a percentage of the average pretetanus f-EPSP over time (in minutes). Inset, two representative f-EPSPs from lesion-stress group, taken $10 \mathrm{~min}$ before and 50-60 $\mathrm{min}$ after LTP are shown. $B$, Trunk blood corticosterone levels assayed ( $\mathrm{I}^{125}$ radioimmunoassay) from the four groups used in the hippocampal slice experiment.
A

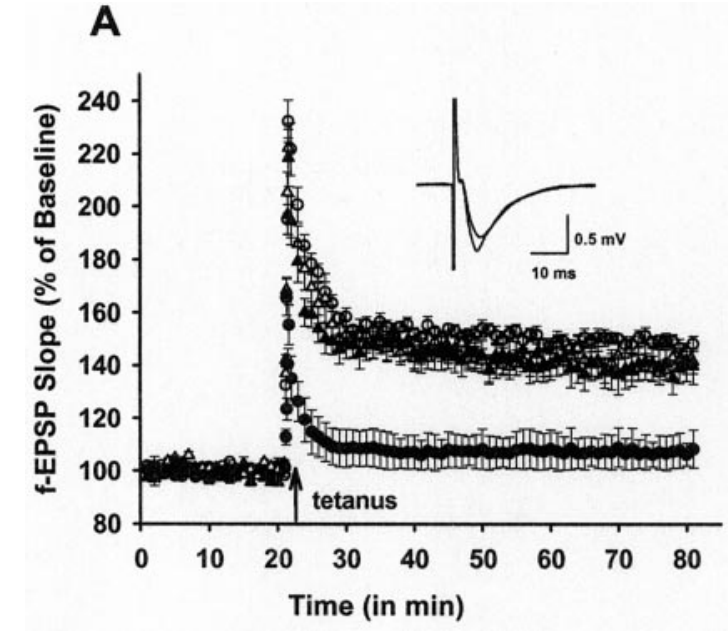

B

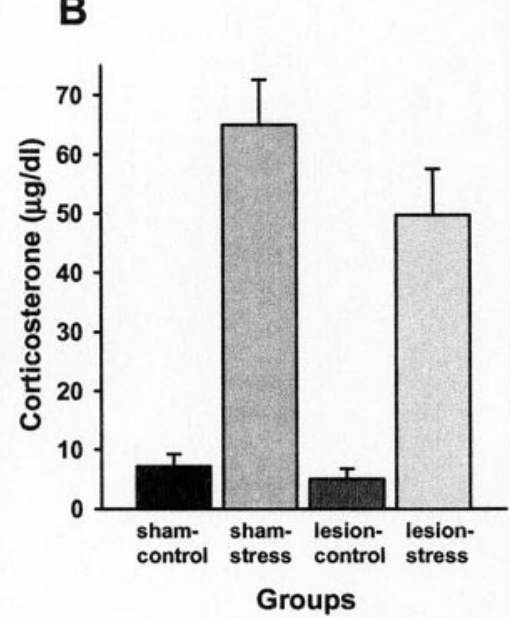



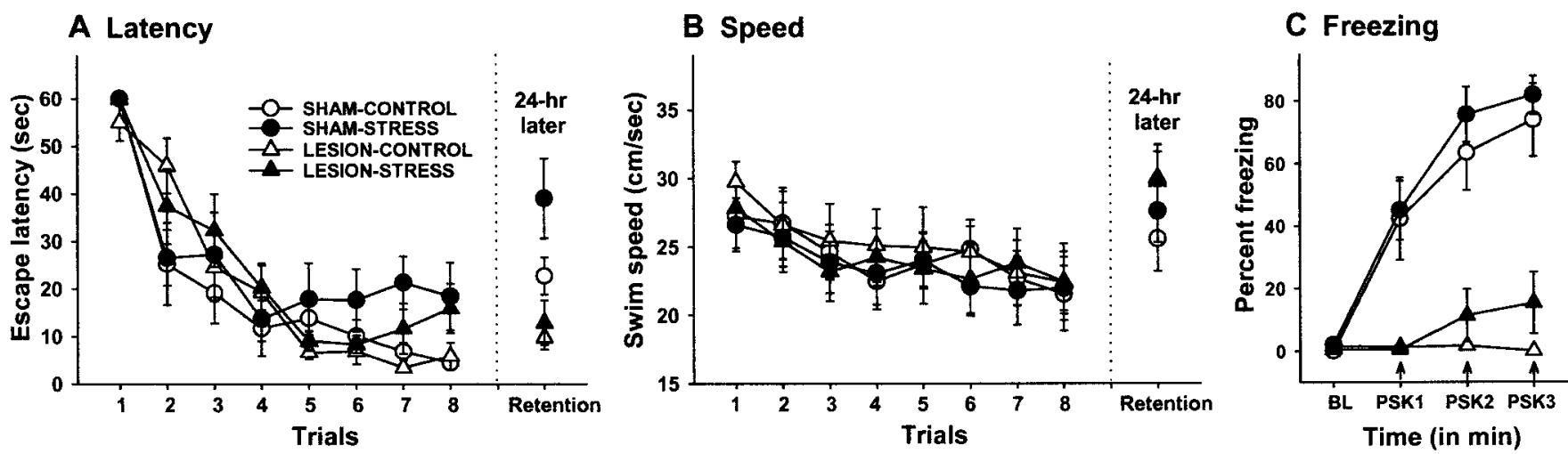

Figure 3. Effects of amygdalar lesions and stress on spatial memory and fear conditioning. $A$, Mean ( \pm SE) latencies to find a submerged platform from sham-control (open circles, $n=8$ ), sham-stress ( filled circles, $n=9$ ), lesion-control (open triangles, $n=9$ ), and lesion-stress ( filled triangles, $n=9$ ) animals during acquisition and a single retention test. $B$, Mean $( \pm \mathrm{SE})$ swim speed (centimeters per second) of four groups during acquisition and a single retention test. $C$, Mean $( \pm \mathrm{SE})$ percentage postshock $(P S K)$ freezing during the 1 min baseline $(B L)$ and during the three 1 min intershock intervals.
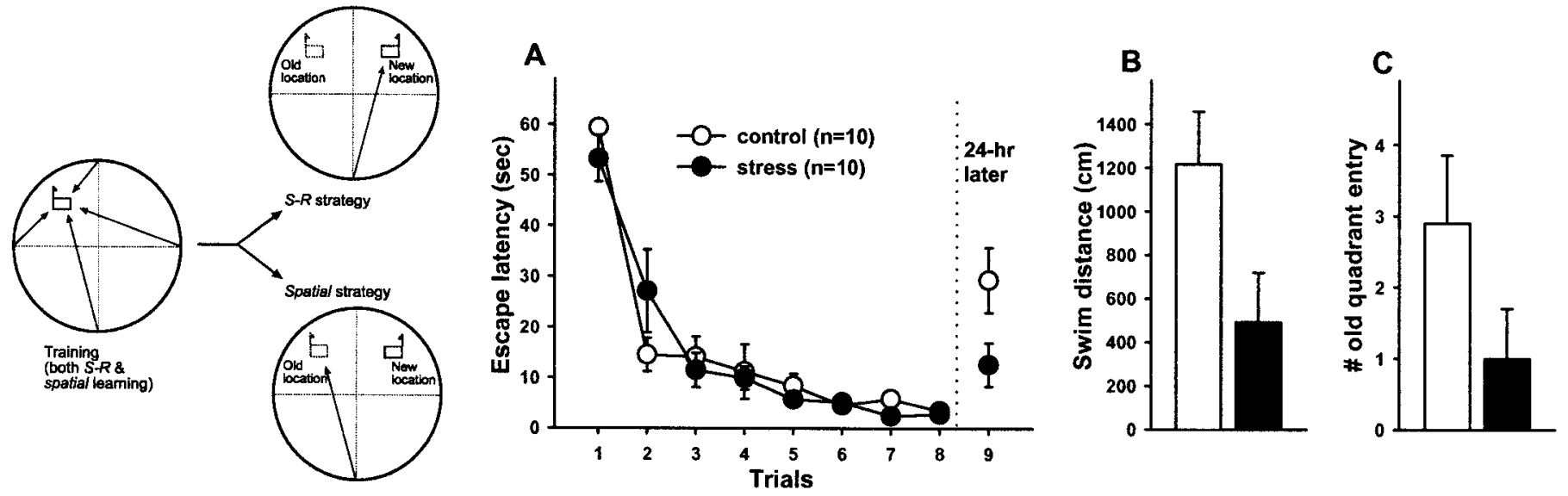

Figure 4. Left, Fixed location-visible platform water maze paradigm for assessing stress effects on the relative use of S-R and spatial memory. $A$, Mean $( \pm$ SE) latency to find a submerged platform marked with a visually salient pole from control (open circles, $n=10)$ and stress $($ filled circles, $n=10)$ animals during the acquisition trials (1-8) and on a single test trial (9). B, Mean ( \pm SE) distance to find a submerged platform marked with a visually salient pole on a single test trial. $C$, Mean number of old quadrant entry (where the platform was located during training).

(10 of 10) initially swam to the original platform location (preferentially using a spatial strategy) before swimming to the visible platform now located in a new quadrant. In contrast, 5 of 10 stress animals swam directly to the new platform location [preferentially using a stimulus-response (S-R) strategy], whereas the remaining 5 animals swam to the original platform location before the new platform location (preferentially using a spatial strategy). The swim distance to the new platform location and the number of old quadrant entry measures (Fig. $4 B, C$ ) also indicate that stress enhances the use of an S-R strategy in this task.

\section{DISCUSSION}

The present findings demonstrate that amygdalar lesions effectively block stress effects on hippocampal LTP and hippocampaldependent memory and are consistent with previous reports that amygdalar lesions prevent other effects of stress, including gastric erosion (Henke, 1990) and analgesia (Helmstetter, 1992). Specifically, we found that hippocampal slices obtained from sham animals exposed to stress exhibited LTP impairments in the CA1 area, whereas slices from sham animals not exposed to stress demonstrated robust LTP, replicating earlier in vitro and in vivo findings of stress-induced impairment of LTP (Foy et al., 1987; Shors et al., 1989; Diamond and Rose, 1994; Kim et al., 1996; Xu et al., 1997). In contrast, LTP was observed reliably in hippocampal slices prepared from amygdala-lesioned animals, regardless of whether or not they experienced stress. Similarly, we observed that amygdalar lesions also blocked stress-induced memory impairments when rats were tested in a hidden platform water maze task that has previously been shown to be hippocampus-based (Packard et al., 1994; Packard and Teather, 1998). Thus, our findings that the amygdala is critically involved in mediating stress effects on hippocampal LTP and hippocampal-dependent memory are consistent with the view that one function of the amygdala is to modulate memory processes in other brain structures, such as the hippocampus (Gallagher and Kapp, 1978; Ikegaya et al., 1994; Packard et al., 1994; Cahill and McGaugh, 1998; Packard and Teather, 1998; Roozendaal et al., 1998; Packard and Chen, 1999; McGaugh, 2000).

In the present study, sham lesion animals exposed to $1 \mathrm{hr}$ of uncontrollable stress (60 tailshocks and restraint) before undergoing water maze training (pretraining stress effects) exhibited impairments in spatial memory when tested $24 \mathrm{hr}$ later. In another study (de Quervain et al., 1998), a relatively milder three footshock stress (lasting $<1 \mathrm{~min}$ ) that was presented before a retention test (pretesting stress effects) impaired performance in 
a water maze spatial task in a time-dependent manner (i.e., retention was impaired $30 \mathrm{~min}$ poststress but not $2 \mathrm{~min}$ or $4 \mathrm{hr}$ poststress) that corresponds to the corticosterone levels at the time of testing. It appears then that pretraining exposures to a relatively intense and longer-lasting stress (used in the present study) can affect spatial memory in a manner that does not directly correspond to the corticosterone levels at the time of testing (24 hr later).

Because there is no evidence that three footshock stress influences hippocampal plasticity (i.e., LTP), it would be important to investigate whether or not these two different magnitudes of stress produce similar pretraining and pretesting effects on hippocampal-dependent memory.

Interestingly, using the present training-testing procedures, lesioning the amygdala per se seems to enhance the performance in the hidden platform water maze task. This finding differs from a previous study (Sutherland and McDonald, 1990) that found neither enhancing nor impairing effects of amygdalar lesions on a spatial version of the water maze task when animals were trained across several days. It is conceivable that high levels of stress hormones (such as epinephrine and glucocorticoids) are released during the eight massed water maze training trials, which might normally produce memory impairing effects in the amygdalaintact animals. Thus, this finding is consistent with the accumulating evidence indicating that amygdala function is necessary for intrahippocampally administered drugs to modulate (enhance or impair) consolidation of hippocampal-dependent (e.g., spatial) memory and for mediating memory modulatory effects of stress hormones (Cahill and McGaugh, 1991; Packard et al., 1994; Roozendaal and McGaugh, 1996, 1997; Roozendaal et al., 1998; Packard and Teather, 1998; Packard and Chen, 1999; McGaugh, 2000).

It is also significant that amygdalar lesions did not affect Schaffer collateral-commissural-CA1 LTP in hippocampal slices from unstressed animals. Recent studies suggest that the amygdala influences LTP in the hippocampus. For instance, electrolytic lesions to the basolateral (but not central) nuclei of the amygdala have been shown to significantly attenuate perforant path-dentate gyrus LTP in vivo (Ikegaya et al., 1994), whereas highfrequency stimulation of the amygdala augmented LTP (Ikegaya et al., 1996). It now appears that stimulation of the amygdala induces a time-dependent biphasic effect on hippocampal LTP (an immediate excitatory effect and a longer-lasting inhibitory effect) (Akirav and Richter-Levin, 1999). Additionally, intraamygdala infusions of NMDA receptor antagonists have been found to impair dentate gyrus LTP (without affecting the baseline synaptic response), suggesting that NMDA receptors in the amygdala might be involved in influencing LTP (Ikegaya et al., 1995). In the present study, however, although amygdalar lesions (which included both central and basolateral nuclei) blocked stress effects on CA1 LTP in vitro, the lesions did not affect LTP in unstressed animals. Thus, it is possible that the amygdala may differentially influence synaptic plasticity in different regions of the hippocampus.

Although stress impaired retention of hippocampal-dependent memory in a hidden platform water maze task, the same stress enhanced the relative use of hippocampal-independent S-R memory in a fixed location-visible platform water maze task in which both hippocampal-dependent and caudate-dependent memory systems are engaged (McDonald and White, 1994). The effects of stress on behavior in this task are similar to those of fornix lesions, which also result in enhanced use of S-R behavior relative to normal animals (McDonald and White, 1994). Thus, both stress (presumably via impairing hippocampal LTP) and fornix lesions (via disrupting hippocampal afferent-efferent pathways) impair the use of spatial information and facilitate the use of S-R information in the acquisition of an escape response to a visible platform in a fixed location. Similarly, stress (Shors et al., 1992; Shors and Mathew, 1998) and hippocampal lesions (Schmaltz and Theios, 1972; Port et al., 1985) have been shown to facilitate the acquisition of hippocampal-independent (but cerebellardependent) delay eyeblink conditioning (Kim et al., 1995; Kim and Thompson, 1997). It has also been reported that infusions of NMDA receptor antagonists into the amygdala before stress effectively block stress-induced facilitation of eyeblink conditioning (Shors and Mathew, 1998). Thus, it would be important to test whether NMDA receptor antagonists in the amygdala would also block stress-induced enhancement of hippocampal-independent S-R memory as well as stress-induced impairment in hippocampal LTP and spatial memory. At any rate, our findings are consistent with the general notion that amygdala activation can influence both hippocampal-dependent and hippocampal-independent memory (Packard et al., 1994; McGaugh, 2000)

It is generally viewed that there are multiple memory systems that are subserved by different brain substrates (Packard et al., 1989, 1994; Packard and McGaugh, 1992; Squire and Zola, 1996; Thompson and Kim, 1996). Under normal conditions, however, competition for control of learned behavior may arise among these systems. For example, although the hippocampus is not essential for delay eyeblink conditioning (Schmaltz and Theios, 1972; Kim et al., 1995), hippocampal lesions can facilitate the acquisition of delay eyeblink conditioning (Port et al., 1985), pretraining LTP saturation in the hippocampus accelerates the rate of delay eyeblink conditioning (Berger, 1984), and PKC $\gamma$ mutant mice (deficient in the $\gamma$ isoform of protein kinase $C$ ) with a moderate impairment in hippocampal LTP (Abeliovich et al., 1993) exhibit facilitated acquisition of delay eyeblink conditioning (Chen et al., 1995). In addition, lesions of the hippocampal system facilitate the acquisition of caudate-dependent S-R learning in a win-stay radial maze task (Packard et al., 1989; McDonald and White, 1993). Together, these results indicate that during hippocampal-independent learning (e.g., delay eyeblink conditioning, S-R learning), the hippocampus may be engaged in processing information (e.g., context) (Good and Honey, 1991; Kim and Fanselow, 1992; Phillips and LeDoux, 1992) that might interfere with the formation or expression of hippocampalindependent memory. Thus, stress-induced alterations in synaptic plasticity that selectively affect hippocampal memory processes may inhibit the competitive interference between hippocampaldependent and hippocampal-independent memory systems and thereby enhance performance in nonhippocampal learning tasks.

With regard to stress effects on hippocampal LTP, it has been reported previously that there is a biphasic relationship between level of corticosterone and magnitude of LTP (Diamond et al., 1992), with both low (via adrenalectomy) and high (via exogenous administration) levels of corticosterone impairing LTP. In addition, corticosterone has been shown to affect the intrinsic properties of hippocampal neurons (e.g., prolonging the afterhyperpolarization) (Joels and De Kloet, 1989; Kerr et al., 1989) that would reduce cell excitability. Behaviorally, rats that were administered corticosterone at doses comparable with those observed during natural stress were found to be impaired in spatial learning (Bodnoff et al., 1995). Given these findings, it is surprising that amygdalar lesions effectively blocked stress effects on hippocam- 
pal LTP and spatial memory without significantly affecting the increase in corticosterone secretion in response to stress. Our results suggest that this increase in corticosterone levels is not a sufficient condition to mediate stress effects on hippocampal plasticity and learning. This view is also supported by findings that LTP is reduced further in adrenalectomized rats after stress and is not restored by exogenous administration of corticosterone (Shors et al., 1990), and that in normal animals administered with dexamethasone (a synthetic glucocorticoid that blocks the HPA axis activity), stress-induced impairments in LTP nonetheless occurred (Foy et al., 1990). Collectively, these data indicate that multiple factors (in addition to glucocorticoids) mediate stress effects on hippocampal functioning.

In conclusion, the current findings suggest that alterations in hippocampal plasticity subsequent to stress might be caused by excessive modulatory effects of the amygdala during the stress experience. If amygdalar modulation of hippocampal physiology occurs during stress, then this effect must have a long duration because it was observed in hippocampus isole. It is now of interest to characterize the neuroanatomical-neurochemical projections from the amygdala to the hippocampus to further elucidate the modulating mechanisms of stress on neural plasticity and memory processes.

\section{REFERENCES}

Abeliovich A, Paylor R, Chen C, Kim JJ, Wehner JM, Tonegawa S (1993) PKC $\gamma$ mutant mice exhibit moderate deficits in contextual learning. Cell 75:1263-1271.

Aggleton JP (1986) A description of the amygdalo-hippocampal interconnections in the macaque monkey. Exp Brain Res 64:515-526.

Akirav I, Richter-Levin G (1999) Biphasic modulation of hippocampal plasticity by behavioral stress and basolateral amygdala stimulation in the rat. J Neurosci 19:10530-10535.

Berger TW (1984) Long-term potentiation of hippocampal synaptic transmission affects rate of behavioral learning. Science 224:627-630.

Bliss TVP, Collingridge GL (1993) A synaptic model of memory: longterm potentiation in the hippocampus. Nature 361:31-39.

Bodnoff SR, Humphreys AG, Lehman JC, Diamond DM, Rose GM, Meaney MJ (1995) Enduring effects of chronic corticosterone treatment on spatial learning, synaptic plasticity, hippocampal neuropathology in young and mid-aged rats. J Neurosci 15:61-69.

Bremner JD, Scott TM, Delaney RC, Southwick SM, Mason JW, Johnson DR, Innis RB, McCarthy G, Charney DS (1993) Deficits in short-term memory in posttraumatic-stress-disorder. Am J Psychiatry 150:1015-1019.

Cahill L, McGaugh JL (1991) NMDA-induced lesions of the amygdaloid complex block the retention-enhancing effect of posttraining epinephrine. Psychobiology 19:206-210.

Cahill L, McGaugh JL (1998) Mechanisms of emotional arousal and lasting declarative memory. Trends Neurosci 21:294-299.

Chen C, Kano M, Abeliovich A, Chen L, Bao S, Kim JJ, Hashimoto K, Thompson RF, Tonegawa S (1995) Impaired motor coordination correlates with persistent multiple climbing fiber innervation in $\mathrm{PKC} \gamma$ mutant mice. Cell 83:1233-1242.

de Quervain D, Roozendaal B, McGaugh JL (1998) Stress and glucocorticoids impair retrieval of long-term spatial memory. Nature 394:787-790

Diamond DM, Rose GM (1994) Stress impairs LTP and hippocampaldependent memory. Ann NY Acad Sci 746:411-414.

Diamond DM, Bennett MC, Fleshner M, Rose GM (1992) Inverted-U relationship between the level of peripheral corticosterone and magnitude of hippocampal primed burst potentiation. Hippocampus 2:421-430.

Eichenbaum H, Otto T, Cohen NJ (1992) The hippocampus-what does it do? Behav Neural Biol 57:2-36.

Foy MR, Stanton ME, Levine S, Thompson RF (1987) Behavioral stress impairs long-term potentiation in rodent hippocampus. Behav Neural Biol 48:138-149.

Foy MR, Foy JG, Levine S, Thompson RF (1990) Manipulation of pituitary-adrenal activity affects neural plasticity in rodent hippocampus. Psychol Sci 3:201-204.

Gallagher M, Kapp BS (1978) Manipulation of opiate activity in the amygdala alters memory processes. Life Sci 23:1973-1978.

Gallagher M, Schoenbaum G (1999) Functions of the amygdala and related forebrain areas in attention and cognition. Ann NY Acad Sci 877:397-411.
Good M, Honey RC (1991) Conditioning and contextual retrieval in hippocampal rats. Behav Neurosci 105:499-509.

Hebb DO (1949) The organization of behavior: a neuropsychological theory. New York: Wiley.

Helmstetter FJ (1992) The amygdala is essential for the expression of conditional hypoalgesia. Behav Neurosci 106:518-528.

Henke PG (1981) Attenuation of shock-induced ulcers after lesion in the medial amygdala. Physiol Behav 27:143-146.

Henke PG (1990) Limbic system modulation of stress ulcer development. Ann NY Acad Sci 597:201-206.

Holland PC, Han JS, Gallagher M (2000) Lesions of the amygdala central nucleus alter performance on a selective attention task. J Neurosci 20:6701-6706.

Ikegaya Y, Saito H, Abe K (1994) Attenuated hippocampal long-term potentiation in basolateral amygdala-lesioned rats. Brain Res 656:157-164.

Ikegaya Y, Saito H, Abe K (1995) Amygdala $N$-methyl-D-aspartate receptors participate in the induction of long-term potentiation in the dentate gyrus in vivo. Neurosci Lett 192:193-196.

Ikegaya Y, Saito H, Abe K (1996) The basomedial and basolateral amygdaloid nuclei contribute to the induction of long-term potentiation in the dentate gyrus in vivo. Eur J Neurosci 8:1833-1839.

Joels M, De Kloet R (1989) Effects of glucocorticoids and norepinephrine on the excitability in the hippocampus. Science 245:1502-1505.

Kerr DS, Campbell LW, Hao SY, Landfield PW (1989) Corticosteroid modulation of hippocampal potentials: increased effect with aging. Science 245:1505-1509.

Kim JJ, Fanselow MS (1992) Modality specific retrograde amnesia of fear. Science 256:675-677.

Kim JJ, Thompson RF (1997) Cerebellar circuits and synaptic mechanisms involved in classic eyeblink conditioning. Trends Neurosci 20: 177-181.

Kim JJ, Yoon KS (1998) Stress: metaplastic effects in the hippocampus. Trends Neurosci 21:505-509.

Kim JJ, Fanselow MS, DeCola JP, Landeira-Fernandez J (1992) Selective impairment of long-term but not short-term conditional fear by the $N$-methyl-D-aspartate antagonist APV. Behav Neurosci 106:591-596.

Kim JJ, Rison RA, Fanselow MS (1993) Effects of amygdala, hippocampus, and periaqueductal gray lesions on short- and long-term contextual fear. Behav Neurosci 107:1093-1098.

Kim JJ, Clark RE, Thompson RF (1995) Hippocampectomy impairs the memory of recently, but not remotely, acquired trace eyeblink conditioned responses. Behav Neurosci 109:195-203.

Kim JJ, Foy MR, Thompson RF (1996) Behavioral stress modifies hippocampal plasticity through $N$-methyl-D-aspartate receptor activation. Proc Natl Acad Sci USA 93:4750-4753.

Krettek JE, Price JL (1977) Projections from the amygdaloid complex and adjacent olfactory structures to the entorhinal cortex and subiculum in the rat and cat. J Comp Neurol 172:723-752.

LeDoux JE (1994) Emotion, memory and the brain. Sci Am 270:50-57.

Lee H, Kim JJ (1998) Amygdala NMDA receptors are critical for new fear learning in previously fear-conditioned rats. J Neurosci 18:8444-8454.

Luine V, Villegas M, Martinez C, McEwen BS (1994) Repeated stress causes reversible impairments of spatial memory performance. Brain Res 639:167-170

Maier SF, Seligman MEP (1976) Learned helplessness: theory and evidence. J Exp Psychol Gen 105:3-45.

Maren S, Fanselow MS (1996) The amygdala and fear conditioning: has the nut been cracked? Neuron 16:237-240.

McDonald RJ, White NM (1993) A triple dissociation of memory systems: hippocampus, amygdala, and dorsal striatum. Behav Neurosci 107:3-22.

McDonald RJ, White NM (1994) Parallel information processing in the water maze: evidence for independent memory systems involving dorsal striatum and hippocampus. Behav Neural Biol 61:260-270.

McEwen BS, Sapolsky RM (1995) Stress and cognitive function. Curr Opin Neurobiol 5:205-216.

McGaugh JL (2000) Memory: a century of consolidation. Science 287:248-251.

Morris RGM, Davis S, Butcher SP (1990) Hippocampal synaptic plasticity and NMDA receptors: a role in information storage? Philos Trans R Soc Lond B Biol Sci 329:187-204.

Newcomer JW, Selke G, Melson AK, Hershey T, Craft S, Richards K, Alderson AL (1999) Decreased memory performance in healthy humans induced by stress-level cortisol treatment. Arch Gen Psychiatry 56:527-533

Packard MG, Chen SA (1999) The basolateral amygdala is a co-factor in memory enhancement produced by intrahippocampal glutamate injections. Psychobiology 27:377-385.

Packard MG, McGaugh JL (1992) Double dissociation of fornix and caudate nucleus lesions on acquisition of two water maze tasks: further evidence for multiple memory systems. Behav Neurosci 106:439-446.

Packard MG, McGaugh JL (1994) Quinpirole and d-amphetamine ad- 
ministration post-training enhances memory on spatial and cued discrimination in a water maze. Psychobiology 22:54-60.

Packard MG, Teather LA (1998) Amygdala modulation of multiple memory systems: hippocampus and caudate-putamen. Neurobiol Learn Mem 69:163-203.

Packard MG, Hirsh R, White NM (1989) Differential effects of fornix and caudate nucleus lesions on two radial maze tasks: evidence for multiple memory systems. J Neurosci 9:1465-1472.

Packard MG, Cahill L, McGaugh JL (1994) Amygdala modulation of hippocampal-dependent and caudate nucleus-dependent memory processes. Proc Natl Acad Sci USA 91:8477-8481.

Phillips RG, LeDoux JE (1992) Differential contribution of amygdala and hippocampus to cued and contextual fear conditioning. Behav Neurosci 106:274-285.

Port RL, Mikhail AA, Patterson MM (1985) Differential effects of hippocampectomy on classical conditioned rabbit nictitating membrane response related to interstimulus interval. Behav Neurosci 99:200-208.

Roozendaal B, McGaugh JL (1996) Amygdaloid nuclei lesions differentially affect glucocorticoid-induced memory enhancement in an inhibitory avoidance task. Neurobiol Learn Mem 65:1-8.

Roozendaal B, McGaugh JL (1997) Basolateral amygdala lesions block the memory enhancing effect of glucocorticoid administration into the dorsal hippocampus of rats. Euro J Neurosci 9:76-83.

Roozendaal B, Sapolsky RM, McGaugh JL (1998) Basolateral amygdala lesions block the disruptive effects of long-term adrenalectomy on spatial memory. Neuroscience 84:453-465.

Sapolsky RM (1992) Stress, the aging brain, and the mechanisms of neuron death. Cambridge, MA: MIT.

Schmaltz LW, Theios J (1972) Acquisition and extinction of a classically conditioned response in hippocampectomiized rabbits. J Comp Physiol Psychol 79:328-333.
Scoville WB, Milner B (1957) Loss of recent memory after bilateral hippocampal lesions. J Neurol Neurosurg Psychiatry 20:11-21.

Seligman MEP, Maier SF (1967) Failure to escape traumatic shock. J Exp Psychol 74:1-9.

Shors TJ, Dryver E (1994) Effects of stress and long-term potentiation (LTP) on subsequent LTP and the theta burst response in the dentate gyrus. Brain Res 666:232-238.

Shors TJ, Mathew PR (1998) NMDA receptor antagonism in the lateral/ basolateral but not central nucleus of the amygdala prevents the induction of facilitated learning in response to stress. Learn Mem 5:220-230.

Shors TJ, Matzel LD (1997) Long-term potentiation: what's learning got to do with it? Behav Brain Sci 20:597-614.

Shors TJ, Seib TB, Levine S, Thompson RF (1989) Inescapable versus escapable shock modulates long-term potentiation in the rat hippocampus. Science 244:224-226.

Shors TJ, Levine S, Thompson RF (1990) Effect of adrenalectomy and demedullation on the stress-induced impairment of long-term potentiation. Neuroendocrinology 51:70-75.

Shors TJ, Weiss C, Thompson RF (1992) Stress-induced facilitation of classical conditioning. Science 257:537-539.

Squire LR, Zola SM (1996) Structure and function of declarative and nondeclarative memory systems. Proc Natl Acad Sci USA 93:13515-13522.

Sutherland RJ, McDonald RJ (1990) Hippocampus, amygdala, and memory deficits in rats. Behav Brain Res 37:57-79.

Teyler TJ (1980) Brain slice preparation: hippocampus. Brain Res Bull 5:391-403

Thompson RF, Kim JJ (1996) Memory systems in the brain and localization of a memory. Proc Natl Acad Sci USA 93:13438-13444.

Xu L, Anwyl R, Rowan MJ (1997) Behavioural stress facilitates the induction of long-term depression in the hippocampus. Nature 387:497500 . 